This item was submitted to Loughborough's Research Repository by the author.

Items in Figshare are protected by copyright, with all rights reserved, unless otherwise indicated.

\title{
A new paradigm for numerical simulation of microneedle based drug delivery aided by histology of microneedle pierced skin
}

PLEASE CITE THE PUBLISHED VERSION

http://www.ukpharmsci.org/default.asp

\section{PUBLISHER}

(c) the authors, Academy of Pharmaceutical Sciences of Great Britain

\section{VERSION}

AM (Accepted Manuscript)

\section{PUBLISHER STATEMENT}

This work is made available according to the conditions of the Creative Commons Attribution-NonCommercialNoDerivatives 4.0 International (CC BY-NC-ND 4.0) licence. Full details of this licence are available at: https://creativecommons.org/licenses/by-nc-nd/4.0/

\section{LICENCE}

CC BY-NC-ND 4.0

\section{REPOSITORY RECORD}

Han, Tao, and Diganta Bhusan Das. 2015. "A New Paradigm for Numerical Simulation of Microneedle Based Drug Delivery Aided by Histology of Microneedle Pierced Skin”. figshare. https://hdl.handle.net/2134/18571. 


\title{
A new paradigm for numerical simulation of microneedle based drug delivery aided by histology of microneedle pierced skin
}

\author{
T. Han, D. B. Das
}

Department of Chemical Engineering, Loughborough University, Loughborough, UK.

\begin{abstract}
A new paradigm for numerical simulation of microneedle based drug delivery is introduced in this paper. The computational domain is acquired from histological image of microneedles pierced skin instead of using the model based on microneedles geometry. The simulation results are compared with experimental data and showing a strong correlation which indicates distinguished accuracy.
\end{abstract}

\section{INTRODUCTION}

Microneedle (MN) is a relatively recent invention and an efficient technology for transdermal drug delivery (TDD). Conventionally, the mathematical models of MNs drug delivery define the shape of the holes created by the MNs in the skin as the same as their actual geometry [1]. The size of the MN holes in the skin is considered to be either the same or a certain fraction of the lengths of the MNs. However, the histological images of the MN treated skin indicate that the real insertion depth is much shorter than the length of the MNs and the shapes may vary significantly from one case to another [2]. In addressing these points, we propose a new approach for modelling MN based drug delivery, which incorporate the histology of $\mathrm{MN}$ pierced skin using a number of concepts borrowed from image processing tools. It is expected that the developed approach will provide better accuracy of the drug diffusion profile. A new computer program is developed to automatically obtain the outline of the MNs treated holes and import these images into computer software for simulation of drug diffusion from MN systems.

\section{MATERIALS AND METHODS}

A MATLAB program has been developed in this work which can automatically acquire the coordinates of various points of the image of the skin sample. These coordinates (i.e., not the image) can then be imported into a numerical simulator to carry out the desired simulations for drug transport in MN treated skin (Fig.1). The method is general, and it would work in both in vitro and/or in vivo conditions provided the skin histology images are available.

\section{RESULTS AND DISCUSSION}

The simulated data from all the histological images are averaged and compared with the experimental results of insulin from our previous study [3]. The initial concentration of the drugs (35 $\mu \mathrm{g} / \mathrm{ml})$ and time durations (4 hrs) of the simulation remain the same with the experiment condition. The results are shown in Fig. 2. From the figure we can see that the predicted concentration of insulin resembled well to the experimental results.

\section{CONCLUSIONS}

This new modelling method can provide a reliable and accurate way to test the quality of MNs design and modelling, as well as simulate experimental studies, e.g., permeation experiments on MN pierced skin using diffusion cell. It is expected that the developed paradigm for numerical simulation of MN based delivery would help the researches to design more efficient MNs systems.

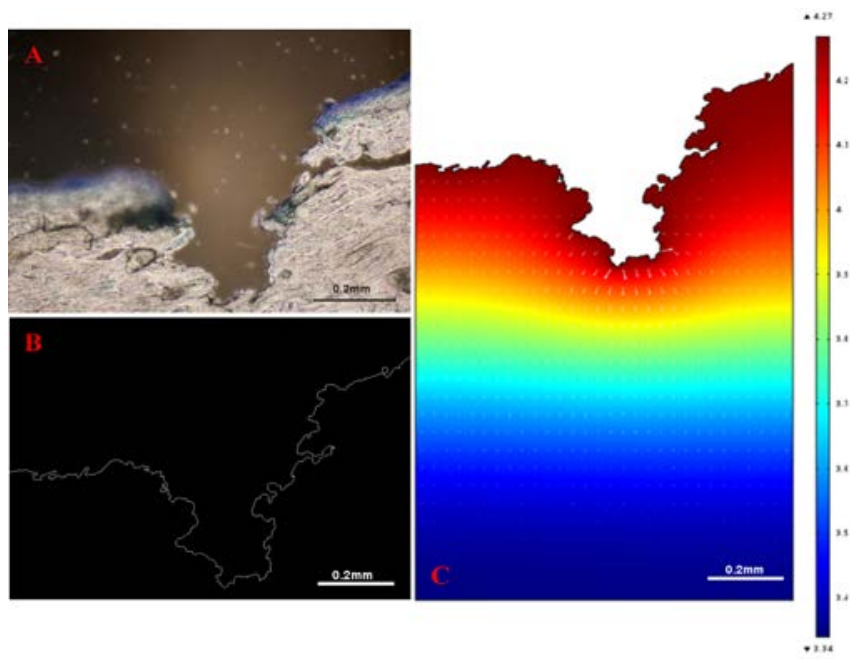

Fig.1 The histological image from cryotome sliced skin is processed by the program and simulated in COMSOL. A) The original image; B) The outline of the skin has been captured; C) Simulated diffusion profile of the target drug molecule (insulin, in this case).

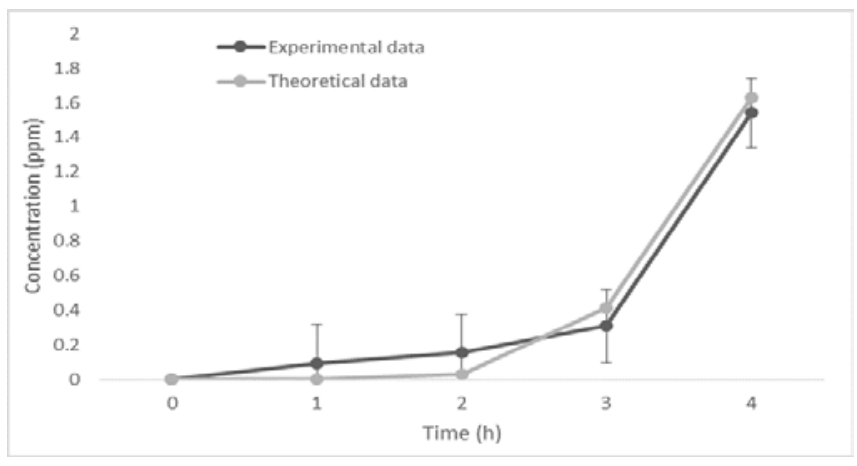

Fig.2 Numerical simulation data compared to the experimental results from our previous papers. The concentration profiles of insulin are presented.

\section{REFERENCES}

[1] P. Aggarwal, C.R. Johnston, "Geometrical effects in mechanical characterizing of microneedle for biomedical applications" Sensors and Actuators B, 102 (2004) 226-234.

[2] T. Han and D.B. Das, "A new paradigm for numerical simulation of microneedle-based drug delivery aided by histology of microneedlepierced skin" J. Pharm. Sci., in press.

[3] K. Cheung, T. Han, D.B. Das, "Effect of force of microneedle insertion on the permeability of insulin in skin" J. Diabetes Sci. Technol., 8 (2014) 444-452. 